\title{
Da onipotência ao desamparo: sobre a relação entre memória filogenética e envelhescência*1
}

\author{
José Carlos Zeppellini Junior*2 \\ Manoel Tosta Berlinck*3
}

\begin{abstract}
Este artigo dedica-se, com base em fragmentos de um caso clínico, a discutir a contribuição dos traços mnêmicos filo $e$ ontogenéticos para a formação de compromissos que acontecem diante do terror suscitado pela velhice. Concomitantemente, apresenta a viabilidade do amparo clínico como alternativa à ameaça de desamparo que emerge da consciência de finitude e salienta a complexidade e a importância do trabalho psíquico de envelhescência como condição fundamental à escuta na transferência.
\end{abstract}

Palavras-chave: Memória, filogenese, envelhescência, desamparo

*1 Este artigo resulta de Tese de Doutorado: Demências: sob o domínio das lembranças; defendida no âmbito do Laboratório de Psicopatologia Fundamental do Programa de Estudos Pós-Graduados em Psicologia Clínica da Pontifícia Universidade Católica de São Paulo, em 2013.

*2 Egresso do Programa de Estudos Pós-Graduados em Psicologia Clínica da Pontifícia Universidade Católica de São Paulo - PUC-SP (São Paulo, SP, Br).

${ }^{* 3}$ Pontifícia Universidade Católica de São Paulo - PUC-SP (São Paulo, SP, Br). 


\section{Fragmento clínico - Primeira parte: A chegada de Lara}

As lágrimas chegaram antes das palavras e o choro, que me trazia à mente a imagem de uma criança assustada, durou um longo tempo. Então, Lara diz: Você vai me achar ridícula...

Eu estou ficando velha... Um cabelo branco aqui, um ali, tudo bem. Mas tudo branco? Um lugar na cabeça em que só nascem cabelos brancos é sinal de que a velhice já está em mim. A partir do momento em que a velhice se firmou, em pouco tempo ela estará espalhada pelo resto do meu corpo.

Estou desesperada... Não estou pronta para a chegada dessa idade. Logo agora que estou desempregada?

Velha e pobre? O que vai ser de mim?

Estou sem dinheiro para arcar com o básico e não vou conseguir pagar meu aluguel por muito mais tempo. Vou precisar voltar para a casa dos meus pais, mas eles já deixaram muito claro que não querem que isso ocorra. Com a minha idade, segundo eles, já deveria ser capaz de cuidar o suficiente de mim mesma...

Pobre, sem família, sem um namorado... Tudo isso se torna mais dificil agora que a velhice se apossou de mim.

Eu sinto que vou acabar sozinha, jogada em um canto com a velhice que já não consigo mais esconder de ninguém... Nem de mim.

\section{Fragmento clínico - Segunda parte: Os caminhos de Lara}

Não consegui vir à sessão da semana passada. Aconteceu algo horrivel! Quando eu estava na rua, vindo para o seu consultório, reparei que não me olhavam e comecei a sentir um desespero imenso! 


\section{ARTIGOS}

Ninguém estava me vendo, eu estava invisivel...

Comecei a ficar em pânico! Meu coração disparou e parecia que minha cabeça iria explodir! Meu peito doía e o ar não prestava para respirar; eu estava sufocando.

Sentei na calçada e comecei a chorar... Tudo tinha ficado preto... Eu estava morrendo!

De repente, chegaram uns moleques, acho que estavam de uniforme escolar e perguntaram se eu precisava de ajuda. Perguntaram o que estava acontecendo... Assim que eles chegaram, comecei a me sentir melhor e o ar voltou a prestar para respirar. Mas o coração continuava doendo. Quando eu me acalmei, tudo aquilo virou uma tristeza horrivel!

Consegui me levantar e voltei para casa. Deitei no sofá e chorei por horas, de soluçar. As pessoas não estavam me enxergando mais... Eu só voltei a aparecer quando estava morrendo. Mesmo assim, de verdade, ninguém parecia se importar muito. Que desespero!

Eu acho que dormi chorando e nem percebi.

As paredes lá do apartamento são finas e eu acordei com o interfone da vizinha tocando. Lembrei que ninguém iria aparecer para me ver naquele dia e comecei a entrar em pânico novamente! Se eu morresse ali, chorando na sala, ninguém ficaria sabendo!

Minhas pernas começaram a tremer e eu comecei a sentir falta de ar e palpitação; eu sentia um medo sem fim! Eu me via morta no chão do apartamento e esquecida, com a pele branca e cheia de poeira em cima. Eu achava que se começasse a gritar, ninguém me ouviria... Comecei a chorar, de novo, até que eu tive uma ideia! Saí correndo igual louca pelo quarto, pela sala, por tudo quanto era canto, caçando todas as moedas e juntando todo o dinheiro que eu ainda tinha. Corri para o banheiro, lavei o rosto e peguei meu telefone. Eu tremia tanto, que fiquei um tempão tentando acessar os números da agenda, mas não conseguia. Depois de um tempão, liguei para uma lanchonete que tem perto de onde eu moro, para ver se a pessoa que atendesse iria me ouvir. Para ter certeza de que eu não tinha desaparecido... Quando uma mulher atendeu a ligação, minha voz embargou e não saía! Deitei no chão e comecei a chorar... Até que a moça perguntou se estava tudo bem! A sensação que eu tive quando ouvi a pergunta que ela me fez, foi a de um alivio profundo. Sabe um alivio que apazigua a alma? Foi assim...

(Silêncio)

Você ficou preocupado comigo, quando eu não apareci na semana passada? 


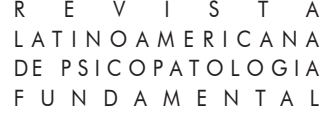

\section{Reminiscências: Filogênese e ontogênese}

$\mathrm{Na}$ apresentação de sua hipótese a respeito da disposição filogenética no que diz respeito à compreensão das neuroses e, mais fundamentalmente, do próprio aparelho psíquico — Freud (1914-1915/1987) aborda questões relevantes ao presente estudo.

O homem primitivo teria, originalmente, existido em um ambiente completa e idealmente favorável. As pulsões sexuais encontravam plena satisfação em meio a riqueza que o cenário lhe disponibilizava, e a oferta de alimentos e abrigo necessária à autoconservação era vasta.

Ocorre que, no curso de sua história, esse homem primitivo defronta-se com a catástrofe glacial e com a emergência de afetos que se desdobraram a partir dela.

Como primeira colocação, afirmaria, portanto, que sob a influência das privações impostas pelo desencadeamento da era glacial a humanidade em geral tornou-se angustiada. (Freud, 1914-1915/1987, p. 75)

Com a chegada de tempos difíceis, esse homem precisou adaptar-se às novas condições para que tanto a autoconservação quanto a conservação da espécie pudessem resistir às adversidades e aos novos perigos. A escassez de alimentos, de abrigos e a interrupção da constância da satisfação sexual, conduziu a espécie a formações mais complexas de grupos, com o intuito de que essas pequenas porções do antigo universo social, pudessem gerenciar de modo mais eficaz as ofertas do ambiente e as demandas internas, priorizando a autoconservação.

(...) Os gêneros alimentícios não eram suficientes para permitir manter vivos os desamparados. A matança dos recém-nascidos certamente encontrou resistência no amor, particularmente das mães narcisistas. (p. 76)

Assim, manter os desamparados vivos tornou-se desvantajoso para a conservação de uma parte do grupo. Não há, nesse texto freudiano (1914-1915/1987), uma determinação precisa a respeito dos fatores constituintes do estado de desamparo, mas é possível pensarmos nessa condição, com base no cenário sobre o qual o texto transcorre, como correlativa à dependência apresentada pelos bebês para com seus cuidadores. Tratar-se-ia, portanto, de um estado no qual o indivíduo encontra-se total ou parcialmente desprovido da potência necessária para lutar, de maneira autônoma, por sua sobrevivência.

Ao dar continuidade à sua especulação filogenética, Freud (1914-1915/ 1987) apresenta as características daquilo que classificou como sendo a 


\section{ARTIGOS}

segunda geração desse povo primitivo, o que nos remete a uma nova fase da cultura humana. $\mathrm{O}$ autor desenvolve, a partir desse ponto, uma rica narrativa a respeito do pai da horda, de suas características fundamentais e de como o grupo orbitou ao redor dessa figura.

O ponto que nos interessa em particular é aquele no qual Freud (1914-1915/1987) relaciona o estado de desamparo com a senescência, no momento em que descreve o processo sucessório do pai no interior do grupo:

(...) Enquanto o mais jovem — de maneira esquemática — graças à intercessão da mãe e, antes de mais nada, pelo envelhecimento do pai e de seu consequente estado de desamparo, tinha a chance de escapar a esse destino (castração) e tornar-se sucessor do pai. (p. 79)

Dessa forma, a velhice é posta como uma etapa da qual o desamparo é característica indelével e, em tempos dificeis, exporia o membro do grupo à ameaça de exclusão — através de um abandono mortífero - em favor da conservação daqueles que permaneciam capazes de garantir benefícios vitais à sua organização social.

O velho tornou-se, portanto, alvo do controle populacional e estava diante do risco de ser submetido ao extermínio em favor dos mais jovens.

Podemos encontrar vestígios que corroboram a prática do abandono, como estratégia de sobrevivência, em tribos nômades ou seminômades que viveram em situação de profunda escassez de recursos. Nessas circunstâncias difíceis, o acúmulo de experiências que poderia garantir ao velho um status de importância e garantir-lhe um valor vital, não representa um bônus que ultrapasse o ônus que é atribuído à sua presença.

A tribo dos Iacutos, esquimós que viviam no nordeste siberiano, caracterizou-se como um povo extremamente pobre, que enfrentou a rigidez do inverno glacial contrabalanceado com estações de verão, nas quais o calor era altíssimo (Beauvoir, 1990).

Nessa civilização, a figura paterna era severa, possuidora de toda a autoridade. Exercia seu poder de forma tirânica e, por vezes, cruel. Tinha o poder de abandonar, vender e, até mesmo, matar os filhos homens. As mulheres do grupo não tinham outra alternativa a não ser submeterem-se aos desígnios do pai/chefe da família.

A velhice, ao chegar, trazia consigo um destino: a exclusão. $O$ velho era deixado para morrer, sem que qualquer piedade the fosse dirigida. A velhice era, portanto, o prenúncio da reviravolta; da onipotência ao desamparo.

Em outra tribo, na floresta da Bolívia, os Sirionos desenvolveram uma cultura extremamente marcada pela miséria de recursos, característica da região 
que habitavam. As relações sociais são pautadas pelo poder que individualmente cada membro apresenta, principalmente no que se refere à autoconservação. $\mathrm{O}$ declínio dessa capacidade representa ônus ao grupo e tal condição culmina no abandono do indivíduo que passa - de alguma maneira - a depender do outro para garantir-lhe o básico da sobrevivência (Beauvoir, 1990).

Essa sociedade não sacrifica a prole, e mantém seus bebês da melhor forma que lhe é possível. Entretanto, os velhos são deixados para trás durante os deslocamentos da tribo.

Podemos, portanto, compreender o comportamento dessas sociedades, como continuidade daquele apresentado nas especulações filogenéticas freudiana (1914-1915/1987), que teriam sido característico do homem primitivo nos tempos de penúria, por consequência da catástrofe glacial.

A velhice, vista como encarnação final da condição de desamparo fruto desta reorganização sociocultural — pode, por deslocamento, ter se tornado um dos representantes simbólicos dessa catástrofe, no corpo e do corpo. Assim, passa a ser concebida como a equivalente biológico da era glacial - um destino ameaçador ao qual todo corpo estaria submetido. Após sua chegada, a riqueza de recursos, até então ideal, se esvai e ocorre um

70 empobrecimento generalizado que traz consigo a ameaça brutal do abandono - que, neste caso, representaria o equivalente da morte.

Em termos metapsicológicos, o encontro entre a atemporalidade do inconsciente e a temporalidade do corpo, marca, também, o conflito entre os ideais do eu. A imortalidade do ideal de eu se presentifica diante da natureza finita do eu ideal quando este é apresentado em sua máxima corporeidade.

A velhice, então, passa a ser temida por ser representante, onto e filogenética, de um desamparo que culmina na morte e, consequentemente, é negada, excluída da experiência narcísica que fundamenta as bases do ideal de eu.

\section{O amparo como posição clínica}

A relação transferencial na qual o clínico se encontra diante da velhice do outro, o remete - demandando atenção especial à contratransferência ao seu próprio trabalho de envelhescência. Este, é condição fundamental para que a senescência transcorra de maneira criativa, tornando suficientemente bem-sucedido o processo adaptativo do eu diante das mudanças às quais está submetido pela natureza, bem como em relação às contínuas demandas internas. 


\begin{abstract}
ARTIGOS
Berlinck (2000) descreve esse trabalho psíquico da seguinte forma:

O que estou propondo, então, é que a envelhescência é uma recriação do eu diante das exigências pulsionais e as novas exigências do corpo que se aproxima da morte. Dadas as funções que o eu desempenha no psiquismo humano - a função sintética e a função administrativa -, ele é uma verdadeira criação cotidiana e é solicitado a constantes rearranjos diante da dinâmica realidade. Um eu rígido, que não responde com criatividade às exigências internas e externas que lhes são feitas, corre o grave risco de rotinizar o cotidiano, podendo acabar como um simples instrumento enfraquecido e estereotipado. A envelhescência é uma boa oportunidade para a flexibilização do eu e, portanto, para a saúde mental do sujeito. (pp. 197-198)
\end{abstract}

A memória da espécie parece ocupar um lugar relevante na estruturação dos conflitos entre a temporalidade do eu e a onipotência atemporal do supereu, na medida em que este se percebe habitando um corpo vulnerável à velhice. Propomos que o terror experimentado diante dessa etapa da vida não tenha na morte a sua causa - por ser esta uma representação negativa e, impossível, para o aparelho psíquico. A ideia de morte parece ser o veículo para o qual se desloca a ameaça de reencontro com a experiência de desamparo original. Esta sim, positiva e presente de maneira indelével como pano de fundo da constituição do próprio aparelho psíquico.

Deste modo, o pathos apresentado por Lara parece não estar relacionado com a finitude da vida, mas sim com o despertar de um registro mnêmico primitivo - tanto filo quanto ontogenético - que revela o retorno da condição de desamparo, e não da morte em si. A revivência da experiência filogenética pode estar representada na dinâmica intrapsíquica através da qual seu processo de envelhescência se desenrola. Esta pode ser reconhecida na repulsa apresentada pelos ideais diante do eu que envelhece e, com isso, reencenaria o risco do eu ser abandonado - como objeto de investimento libidinal - em virtude de seu afastamento radical das expectativas onipotentes.

A emergência desse tempo primitivo, estrangeiro em relação à temporalidade do eu e ao mesmo tempo familiar a todos os membros da espécie, presentifica-se na relação transferencial. Tal peculiaridade torna a transferência um campo suscetível ao surgimento do que Freud (1919/2010) denominou como o "inquietante". Estado este, no qual entramos quando representações que comportam certo grau de familiaridade, mas que deveriam permanecer sob o efeito da repressão e, portanto, ocultos, ascendem à consciência. Torna-se plausível pensarmos na possibilidade do inquietante conter, em parte de sua trama representacional, conteúdos familiares à história 


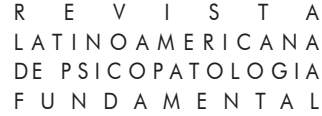

filogenética que, em um primeiro momento, seriam estranhos e ameaçadores ao eu.

Assim, a questão do inquietante, da inquietante estranheza, remete a um núcleo comum aos estados psicopatológicos relacionados ao amedrontador, ao angustiante. $\mathrm{O}$ clínico, portanto, defrontar-se-ia com o aflorar de registros filogenéticos que estão sob o efeito do recalque tanto do paciente quanto dele próprio e que darão contornos peculiares à relação transferencial quando a velhice torna-se tema. Assim, ontogênese e filogênese se apresentam no campo da transferência e a construção de uma narrativa sobre o sofrimento, que nasce como indizível, é uma das vias pelas quais os diversos tempos que fundamentam a vivência do pathos em questão, podem ser integrados, sintetizados e, por fim, elaborados.

Para tanto, a posição clínica de amparo — que constitui-se a partir de uma escuta que sustente, através de um silêncio assegurador, uma retomada das condições básicas de autonomia do eu a partir da presença física do clínico - apresenta-se como facilitadora desse processo. Era de suma importância para Lara ter acesso visual ao outro que the escutava. O silêncio, acolhedor e atento, portava-se como a medida do que poderia ser oferecido 72 em termos de segurança, e a presença física garantia a existência continuada de um outro que ali estava e tinha a intenção de ali permanecer. $\mathrm{O}$ enquadre desse sistema de continência oferecia a Lara, condições de aproximar-se gradualmente da possibilidade de desvincular o desamparo primordial filogenético, do desamparo existencial e fundante de sua ontogênese (em relação ao qual era possível posicionar-se de maneira ativa e criativa).

É de uma base de desamparo que todos partimos, e a partir da qual tornamo-nos autores mais ou menos conscientes de nossa biografia. Assim, torna-se possível reconhecer a velhice não mais como o desamparo, mas como mais uma das experiências vitais nas quais a ilusão de infinitude e onipotência é, de maneira radical, posta à prova.

Reconhecer-se como capaz de encontrar maneiras de sobreviver a essa verdade a respeito da natureza humana é de suma importância para a saúde mental. As funções adaptativa e criativa do eu alicerçam os caminhos para que este se sustente como alvo de interesse libidinal diante da velhice do corpo (protegendo-se, assim, do autoabandono), o que lhe possibilita enfrentar as fantasias de desamparo relativas a essa fase da vida e, consequentemente, projetar-se no tempo futuro ao reconhecer a potência do eu no tempo presente.

O discurso de Lara revela uma incerteza na qual o velho é ameaçado de ser deixado à míngua, rumo à morte. A construção dessa fantasia parece estar, 


\section{ARTIGOS}

em parte, alicerçada simbolicamente em registros filogenéticos nos quais a velhice fora estado determinante para justificar o abandono em situações de penúria. O pathos que se expressa nessa cena faz-se presente através do conflito intrapsíquico que parece reproduzir essa experiência da espécie, e que reside, em forma de potencial mnêmico, no desencontro entre os ideais do eu e a velhice que se impõe de maneira indelével em um corpo que não é mais capaz de desvincular-se de um declínio natural. O encontro entre a atemporalidade do inconsciente e do processo primário, com a temporalidade do organismo, emerge em Lara como um estado de terror.

"Terror", "medo" e "angústia" são empregados erradamente como sinônimos, mas podem se diferenciar de modo claro na sua relação com o perigo. "Angústia" designa um estado como de expectativa do perigo e preparação para ele, ainda que seja desconhecido; "medo" requer um determinado objeto, ante o qual nos amedrontarmos; mas "terror" se denomina o estado em que ficamos ao correr um perigo sem estarmos para ele preparados, enfatiza o fator surpresa. (Freud, 1920/2010, p. 169)

É possível pensarmos em situações nas quais um estado de terror contenha, condensado em sua trama representacional, elementos desconhecidos. O caso Lara nos coloca diante de uma vivência em que terror e angústia parecem se enlaçar e emergir como expressão de um excesso pathos - que, posto em narrativa no enquadre clínico, revela um cenário de assujeitamento diante da velhice e de toda a pobreza que a ela se mistura. Entretanto, há algo que escapa do discurso e que se insere pelo silêncio e pelas lágrimas que dão início ao encontro. Há um choro sem palavras, um choro desesperado, que encharca um rosto que treme ao soluçar. O setting terapêutico acrescenta, ao redor de Lara, um silêncio sem pressa, oferecido em forma de escuta, em forma de presença física e atenta.

Parece-nos que esse intervalo de tempo que caracterizou o início do primeiro atendimento refere-se ao desconhecido, e não ao terror propriamente dito. Esse desconhecido, que propomos ser a emergência reprimida de um estado de perigo filogenético, antes de tornar-se matéria-prima para a construção de uma narrativa a seu próprio respeito, precisa ser vivido em transferência. Ao apresentar sua velhice a um outro, mais jovem, coloca-se sob o risco de ser abandonada e deixada em uma penúria mortal.

Desvincular o velho do restante da tribo era um ato de conservação de grupo. Essa ação ampliava as possibilidades de garantir aos jovens não apenas um maior acesso aos alimentos, mas, também, mobilidade para atacar e defender-se das ameaças externas. Ademais, esse cenário, ao integrar sua cota 
na amplitude dos traços mnêmicos da espécie, realça uma base de conflito na qual essas duas faixas etárias estariam fadadas a não conviverem juntas sem algum nível de ameaça.

O objetivo final do amparo talvez seja o de favorecer a capacidade do paciente de construir, para si mesmo, a possibilidade de reinventar a trajetória que se lhe apresenta como sina; como um destino do qual não se pode fugir. Assim, a angústia relativa à ameaça de abandono, que estaria associada ao declínio corporificado pelo aprofundamento na velhice, invade visceralmente o eu e força a entrada na consciência do que antes permanecia como traço reprimido de memória filogenética. Esse traço, por ser um registro altamente primitivo, não parece estar preservado em forma de imagens ou representações, mas sim por um estado difuso de urgência diante do risco de aniquilação associado ao envelhecimento, vivido sob determinadas circunstâncias de penúria.

Aos olhos de Lara não existiam outras alternativas de trabalho, de laços sociais e possíveis romances. Narrava um estado de apatia e desânimo diante de qualquer demanda por esforço criativo.

Lara repetia frequentemente:

74 Dificil... Muito difícil.

Era como se o caminhar em direção à morte por abandono fosse o seu único destino.

Contudo, ao pensarmos de maneira mais profunda a respeito desse fatalismo, defrontamo-nos, novamente, com a hipótese de que o destino do qual não se pode fugir não é propriamente a morte, mas, sim, o desamparo.

Na mesma proporção em que a ameaça deriva de um tempo pretérito, a única possibilidade de redenção parecia residir igualmente em um tempo primitivo para o qual o processo regressivo transportara o eu.

Para Lara, mover-se era extremamente difícil e, acima de tudo, inútil. Havia, entretanto, um velado estado de espera. Ocorre que os investimentos narcísicos, ao reconhecerem o eu atual como submetido à iminente ameaça de abandono, parece ter encontrado como saída a chegada de um ser ideal que lhe satisfizesse todas as necessidades. Lara passa a esperar a chegada de um outro, que lhe deve cuidados, compreensão e a própria conservação da sua vida. O mundo externo é o local para o qual se projeta o ideal narcísico que não mais é capaz de integrar-se de modo algum ao eu. Tal projeção remete à procura de um outro compatível com tamanha expectativa, o que parece, regressivamente, colocar Lara novamente à espera de uma mãe ideal. Ela narra a espera por um ser que se debruce sobre seu corpo e lhe dê garantias. 


\section{ARTIGOS}

Os mecanismos de defesa que entram em ação para proteger Lara dos terrores oriundos do encontro com sua própria velhice, articulam um processo regressivo no qual filogênese e ontogênese parecem encontrar-se. Essa união ocorre em uma teia representacional na qual as fantasias narcísicas se apresentam como trama nuclear e através das quais ocorre um trabalho de síntese entre estes dois tempos. Nelas, as necessidades de Lara devem ser satisfeitas por meio de relações que simulem o encontro mãe/bebê, constituindo, assim, uma via não apenas de superar a morte, mas, e talvez acima disto, romper com o estado de abandono.

Os registros mnêmicos de sua própria experiência narcísica, suficientemente bem-sucedida, parecem entrar na equação psíquica que compõe a estrutura das formações de compromisso diante do pathos que se the apresenta. $\mathrm{O}$ encontro do registro no qual a velhice fora - em certo momento da espécie - motivo de abandono absoluto e exclusão, com os registros ontogenéticos de sua experiência mais radical de desamparo (vivida na passagem entre o narcisismo primário e o secundário) promove o embate entre um destino que culminou em morte e um outro que culminou na continuidade de sua existência. Este parece ser o motivo pelo qual a regressão do eu ao período de dependência infantil faz-se presente de maneira tão intensa. Em virtude da semelhança entre as duas experiências, aquela na qual a vida foi garantida surge como a única resposta para as ameaças que dominaram Lara.

Deste modo, o estado regressivo que promoveu a identificação do eu com o registro mnêmico do abandono primordial ofereceu, também, a possibilidade de Lara ter esperanças, aguardando o retorno do outro ideal (que se mescla aqui, com as projeções de seus próprios ideais, que romperam com o eu e passaram a olhá-lo como estrangeiro e insuficiente).

Lara revela, assim, suas resistências — um estado melancólico de letargia que a mantém praticamente imóvel - e um ímpeto em recusar qualquer possibilidade de sair de maneira autônoma de um existir que justifique seus apelos por cuidados. Renovar-se e responsabilizar-se por ser a condutora de sua vida, passa a ser uma ameaça tão grande quanto o abandono em si. Os ganhos secundários associados às fantasias de retorno aos braços de uma mãe ideal, que culminariam em um afastamento de todas as questões que constituem o dia a dia de uma vida adulta, reforçam a convicção de que esta é a única saída que lhe resta. Dessa maneira, os terrores construídos a partir dos traços mnêmicos filogenéticos tornam-se, também, fundamentais. São as ameaças que deles florescem, que justificam a adesividade da libido em seu par oposto, que se apresenta como o anseio por uma vida que deixe 
de lhe cobrar engajamento profissional, laços sociais e cuidados com a própria saúde. Surge uma solução que tanto lhe protege do que fora o destino tenebroso do velho na história da espécie, quanto do destino do adulto de ser autor daquilo que lhe cabe em sua própria biografia. A regressão para um viver infantil parece dar conta dos dois grupos de ameaças, garantindo a Lara a continuidade de sua existência e satisfazendo de maneira ideal as suas necessidades. Teríamos, portanto, um cenário no qual filogênese e ontogênese se condensam e dão os contornos singulares que fundamentam o universo páthico do qual Lara nos fala.

Havia, contudo, uma ruptura nesse processo de repetição dos sintomas. Lara deslocava-se semanalmente, apesar de chorar a respeito de sua imobilidade senil, ao consultório nos quais as sessões eram realizadas.

A posição clínica de amparo sustentava-se justamente nesta fissura, que contradizia a compulsão a repetição e subsistia na relação transferencial.

$\mathrm{O}$ amparo oferecia à Lara a possibilidade de construir uma nova perspectiva diante de terrores que ignoravam suas potencialidades. Esse enquadramento visava favorecer que as reminiscências filogenéticas pudessem ser integradas ao tempo presente, pela formação de um discurso que 76 implicasse, cada vez mais, as funções sintéticas do eu. Assim, ao romper com a certeza do abandono, tornava-se possível incrementar o registro filogenético com o ontogenético e, a partir dessa junção, erigir uma nova história da qual Lara, gradualmente, se fazia presente como elemento modificador. E, ao ir apoderando-se de sua própria história, escapando do exílio que a memória da espécie representava, retoma o trabalho de envelhescência e reinsere-se em um espaço existencial potencialmente criativo, que lhe dava as ferramentas para enfrentar suas marcas ontogênicas, bem como os desafios que o tempo presente e futuro lhe reservavam.

A posição clínica de amparo constituía-se em paralelo à construção de uma narrativa a respeito dos horrores que Lara vivia visceralmente. Construiu-se, principalmente, como uma escuta possível diante dos estados de pânico que pareciam afastá-la da linguagem, e configuravam um apelo a um encontro também anterior ao da fala.

Ter ataques repetidos de pânico constitui uma tentativa, por assim dizer, de esvaziar a morte do seu conceito incognoscível, por meio de uma atualização-antecipação do momento de entrada nesse estado de desvalia; trata-se de um esforço por "tocar" o impossível, aquilo que escapa sempre e necessariamente ao psíquico, isto é, um esforço de controlar o momento de abandono por parte do outro suposto protetor e fiador do mundo. (Pereira, 2008, p. 39) 


\section{ARTIGOS}

O amparo clínico não implica uma recusa do estado de desamparo, ou até mesmo em um ato de remendá-lo em um todo ilusório. Ao contrário, visa resgatar o caráter criativo que se apresenta a partir do espaço potencial que apenas a condição fundamental de desamparo possibilita.

O potencial criativo proporcionado por uma escuta capaz de amparar sem recusar a validade do desamparo, foi o caminho clínico que favoreceu o reencontro de Lara com o ineditismo, contribuindo para o seu desvencilhamento da repetição sintomática.

A título de conclusão do presente estudo, voltamos ao texto de Freud (1914-1915/1987):

A angústia comporta no cerne de sua indeterminação alguma coisa da ordem de uma memória em estado de suspensão (ainda que seja através da desconcertante hipótese de uma memória filogenética). (p. 24)

Essa memória em estado de suspensão se apresentou em forma de angústia e foi posta em movimento através da transferência. Debruçamo-nos sobre a relação entre os registros filogenéticos e ontogenéticos na construção do quadro psicopatológico apresentado por Lara e sustentamos, assim, a hipótese de que a construção gradativa de um amparo clínico the tornou possível historicizar, via construção de uma narrativa, o que antes era exprimido exclusivamente pela via do pathos.

\section{Fragmento clínico - Terceira parte: A dúvida de Lara: uma dívida?}

Estava olhando minha caixa postal e vi que havia uma mensagem de uma chefe antiga que eu tive. Fiquei com medo de olhar e, de repente, ser algum tipo de cobrança ou de crítica. Fiquei um tempão pensando se deixei algo incompleto, ou se estava devendo alguma coisa... No final das contas, era uma oferta de job como free-lancer... Ainda nem respondi... Mas isso não me sai da cabeça.

\section{Referências}

Beauvoir, S. (1990). A velhice. Rio de Janeiro, RJ: Nova Fronteira.

Berlinck, M. T. (2000). Psicopatologia Fundamental. São Paulo, SP: Escuta. 


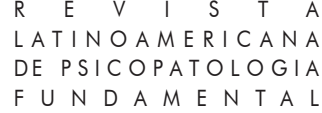

Freud, S. (1987). Neuroses de Transferência: Uma Sintese. Rio de Janeiro, RJ: Imago. (Trabalho original publicado em 1914-1915).

Freud, S. (2010). Além do princípio do prazer. In História de uma neurose infantil: ("O homem dos lobos"): além do princípio do prazer e outros textos (1917 - 1920). São Paulo, SP: Companhia das Letras. (Trabalho original publicado em 1920).

Freud, S. (2010). O inquietante. In Histórias de uma neurose infantil: ("O homem dos lobos"): além do princípio do prazer e outros textos (1917-1920). São Paulo, SP: Companhia das Letras. (Originalmente publicado em 1919).

Pereira, M. E. C. (2008). Pânico e desamparo: um estudo psicanalítico. São Paulo, SP: Escuta.

\section{Resumos}

(From omnipotence to abandonment; about the relationship between phylogenetic memory and aging)

Based on fragments of a clinical case, this paper discusses the contribution of phylo and ontogenetic mnemonic traits to the formation of commitments that occur

78 facing the terror of old age. At the same time, it presents the feasibility of clinical support as an alternative to the threat of abandonment that emerges from consciousness of finitude, and highlights the complexity and the importance of psychological work referring to aging as a fundamental condition to listening in transference.

Key words: Memory, phylogenesis, aging, abandonment

(De l'omnipotence à la détresse: Sur le rapport entre la mémoire phylogénétique et le vieillissement)

Cet article, basé en partie sur une étude clinique, discute la contribution des traits mnémoniques phylogénétique et ontogénétiques à l'adhésion à des compromis qui s'opèrent face à la crainte suscitée par le vieillissement. Parallèlement, cet article présente la faisabilité du support clinique comme alternative à la menace de la détresse qui se dégage de la prise de conscience de la finitude. Il souligne d'ailleurs la complexité et l'importance du travail psychique sur le vieillissement en tant que condition fondamentale à l'écoute pendant le transfert.

Mots clés: Mémoire, phylogénie, vieillissement, détresse

(De la omnipotencia al desamparo: sobre la relación entre memoria filogenética e envejecimiento)

Este artículo se dedica, basado en los fragmentos de un caso clínico, a discutir la contribución de las huellas mnémicas filo y ontogenéticas, en la formación de 


\begin{abstract}
ARTIGOS
compromisos que se dan ante el terror suscitado por la vejez. Concomitantemente, presenta la factibilidad del apoyo clínico, como alternativa a la amenaza de desamparo que emerge del conocimiento de la finitud, y refleja la complejidad y la importancia del trabajo psíquico durante el envejecimiento como una condición fundamental para la escucha en la transferencia.
\end{abstract}

Palabras clave: Memoria, filogénesis, envejecimiento, desamparo

(Von der Allmacht zur Hilflosigkeit: Über die Beziehung zwischen der phylogenetischer Erinnerung und dem Alterungsprozess)

Der vorliegende Artikel widmet sich mit Hilfe der Betrachtung eines klinischen Falls der Frage des Beitrags phylogenetischer und ontogenetischer mnemischer Züge zur Bildung von Kompromissen, welche angesichts der Angst vor dem Altern entstehen. Gleichzeitig weist er auf die Durchführbarkeit der klinischen Unterstützung als alternative Lösung gegen die Bedrohung der Hilflosigkeit hin, welche durch das Bewusstsein über die Endlichkeit ausgelöst wird und betont die Komplexität und Wichtigkeit der psychischen Verarbeitung des Alterungsprozess als grundlegende Bedingung des Zuhörens während der Übertragung.

Schlüsselwörter: Erinnerung, Phylogenese, Alterungsprozess, Hilflosigkei

(从全能到无助: 关于系统发生记忆和衰老之间的关系)

本论文通过一临床病例片段的分析，讨论因衰老而唤起的恐惧感，从而引 发了新的本体认知。我们知道这是一种系统发生学现象。与此同时, 作者提出 针对病人在终结意识下产生无助感的时刻, 给病人提供临床支持。作者强调在 衰老症的心理疏导过程中, 精神分析学家的在聆听工作的复杂性和重要性。 关键词: 记忆, 系统发育, 衰老过程, 无助感

Citação/Citation: Zeppelini Junior, J. C., \& Berlinck, M. T. (2017, março). Da onipotência ao desamparo: sobre a relação entre memória filogenética e envelhescência. Revista Latinoamericana de Psicopatologia Fundamental, 20(1), 65-80.

Editores do artigo/Editors: Profa. Dra. Ana Maria Rudge e Profa. Dra. Sonia Leite

Recebido/Received: 9.4.2016/ 4.9.2016 Aceito/Accepted: 15.9.2016 / 9.15.2016

Rev. Latinoam. Psicopat. Fund., São Paulo, 20(1), 65-80, mar. 2017 


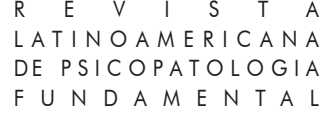

Copyright: (C) 2009 Associação Universitária de Pesquisa em Psicopatologia Fundamental/ University Association for Research in Fundamental Psychopathology. Este é um artigo de livre acesso, que permite uso irrestrito, distribuição e reprodução em qualquer meio, desde que o autor e a fonte sejam citados / This is an open-access article, which permits unrestricted use, distribution, and reproduction in any medium, provided the original authors and sources are credited.

Financiamento/Funding: Os autores declaram não ter sido financiados ou apoiados / The authors have no support or funding to report.

Conflito de interesses/Conflict of interest: Os autores declaram que não há conflito de interesses / The authors have no conflict of interest to declare.

\section{José Carlos Zeppellini Junior}

Psicólogo; Especialista em Psicopatologia pelo NAIPPE/USP; Mestre e Doutor em Psicologia Clínica pela Pontifícia Universidade Católica de São Paulo - PUC-SP (São Paulo, SP, Br); Egresso do Programa de Estudos Pós-Graduados em Psicologia Clínica da Pontifícia Universidade Católica de São Paulo - PUC-SP.

Rua Itacolomi, 333/64 - Higienópolis

01239-020 São Paulo, SP, Br

zeppellini.junior@bol.com.br

\section{Manoel Tosta Berlinck (1936-2016)}

Psicanalista; Ph.D. Cornell University; Professor Títular Aposentado da Unicamp; Professor do Programa de Estudos Pós-Graduados em Psicologia Clínica da Pontifícia Universidade Católica de São Paulo; Diretor do Laboratório de Psicopatologia Fundamental (PUC-SP); Presidente da Associação Universitária de Pesquisa em Psicopatologia Fundamental e Editor da Revista Latinoamericana de Psicopatologia Fundamental.

This is an open-access article, which permits unrestricted use, distribution, and reproduction in any medium for non-commercial purposes provided the original authors and sources are credited. 